\title{
Study on Mechanism in the Use of Resources of Regional Economic Development
}

\author{
Yingjuan Feng \\ School of Economics and Management, Changchun University of Science and Technology \\ Changchun 130021, China \\ Tel: 86-431-8628-7978Ｅ-mail: blessyandm@163.com
}

\begin{abstract}
Resources competitiveness is the basis of regional economic competitiveness. With the development of world economic integration, the mobility of resources strengthens, aggravate the scarcity of resources. Regional economy would achieve sustainable development, it is necessary to use the resources which they have possessed fully, scientifically and reasonably. In this paper, we are in four areas including optimize the allocation of resources, recycling of resources, comprehensive utilization of resources, as well as value-added use of resources to conduct in-depth study of the mechanism in the use of resources of regional economic development.
\end{abstract}

Keywords: Regional economy, Resources, Use

\section{Introduction}

The 21st century, accompanied by the development of world economic integration, international markets become domestic one, operation of enterprises becomes internationalization, and result in a country's resources as part of the world's resources, a country's market becomes part of the global market, the mobility of resources is strengthened. To enhance the Resource's mobility, the scarcity of resources is exacerbated. Accordingly, the basic problem of economics - the issue of resource allocation is more prominent, and the competition is very fierce scramble for resources.

Resources competitiveness is the basis of regional economic competitiveness. Porter in his 1990 publication of "The Competitive Advantage of Nations," put forward the famous theory "The Competitive Advantage of Nations theory", to say that a country's competitive advantages in the elements promotion stage depends largely on the advantages of production factors they owned, namely have cheap labor and rich resources. In fact, if we extend the connotation of resources, regardless of the economy in any period, a country's resource endowment situation will be the basis of its economic development. Therefore, region need to use the resources which they have possessed fully, scientifically, and reasonably, optimize the allocation of resources, enhance the level of the development and utilization of resources and units conversion rate of resources, increase sustainable supply of resources and replacement, and improve the status of resources recycling, to further enhance the regional resources competitiveness.

\section{The Mechanism of Optimize Allocation for Resources}

\subsection{Allocations of Resources and Optimization}

Allocation of resources refers to the distribution in all directions for limited resources (including human, financial, and material, etc.) in a variety of economic systems, and through the degree of systematic goals to inspect efficiency of allocation, its basic meaning including two aspects: static input distribution and dynamic transfer flow or adjusted. From the micro perspective, the allocation of resources is that producer distributes and uses their raw materials for production reasonably, and its goal is to maximize economic benefits, namely achieve the maximum output or minimum input; from a macro perspective, the allocation of resources is dynamic optimization of resources, control, and layout, and its aim is to obtain maximum economic, social and ecological benefits. In conclusion, the allocation of resources is based on a target, according to a certain way, to distribute resources reasonably to various departments of social production as far as possible, expect to achieve the greatest economic, social and ecological benefits, raise the level of welfare of human society. 
Optimization distribution of resources mainly includes two aspects: First, optimal configuration of resources in space or among different departments, including the allocation within the region or sector and between the region or sector; Second, the best distribution of resources at different times, that is dynamic optimization problem of resources.

Therefore, the objective of the allocation of resources is to use and configure optimal of resources, that is, to achieve Pareto optimal state. Further, from the point of view of investment and producers, optimize the allocation of resources is to use minimal input for maximum output, to maximize economic interests; from the consumer's point of view, the purpose of optimizing the allocation of resources to achieve maximum avail, bring the highest welfare; from the Government and the community's point, the purpose of rational distribution of resources is to social justice, the stability of the ecological environment, socio-economic balance and sustainable development.

\subsection{The Necessity to optimize the allocation of resources}

\subsubsection{To optimize allocation of regional resources is the inevitable demand for scarcity of resources}

A region want to develop economy, improve people's living standards, upgrade the economic structure, polish up the living environment, get ahead spiritual and material civilization and so on, the demand of development is infinite, but the resources required to support the development is always limited. Any regional government, whether it is well-off areas or poverty-stricken areas, was always feeling decline in natural resources, hard up of funds, personnel shortages, lack of technology, information incompleteness, in a word, whatever is absent.

Because of the existence of scarcity of resources precisely, it requires that we have to make use of existing resources fully and effectively, that is, optimize the allocation of regional resources to improve the rate of resources conversion and utilization, in order to reap the maximum economic benefits and utility.

\subsubsection{Optimize allocation of resources is a prerequisite for sustainable development of regional economy}

Sustainable supply of regional resources is the premise for regional sustainable development, because resources are the material basis for regional economic development. Regional Sustainable Development consider comprehensively population, environment, resources, economy and social factors, to pursue a sustained, healthy and harmonious development, in order to ensure society, economy, population, resources and environment achieving mutual coordination, health continuing, follow the road which not also meeting the needs of contemporary people, but only meeting the needs of future generations development. This requires that we handle the relationship between resource use and economic development correctly, follow the path of sustainable development, that is, optimize the allocation of resources to achieve sustainable supply of resources.

\section{Mechanism of Resources Recycling}

\subsection{The Meaning of Resources Recycling}

Due to lack of elasticity of supply and demand of resources in the short run, it is necessary to vigorously promote the recycling of resources. Recycling of resources is the core connotation of Circular Economy. In March 2005 the United Arab Emirates capital of Abu Dhabi at the World "Thought Forum" conference, put forward a "5R" which is the new economic thinking of circular economy, that is, "Rethink, Reduce, Reuse, Recycle, Repair ". This expands areas of recycling of resources to the whole regional resource systems from natural resources to human resources, technology resources, social resources and organizational resources.

Starting from the entire resources system, the recycling of resources means: rational development of natural resources; in the production process, through appropriate advanced technology processing energy and raw material into environmentally friendly products as far as possible and realize site reuse (reuse constant); a rational consumption of the final product in the process of circulation and consumption, and finally returned to the production process and reuse of resources; social network maintenance and repair as well as re-use of organizational resources, technology and human resources.

\subsection{Impact of Recycling Resources for Regional Economy}

3.2.1 Via"5R" recycling resources improve the efficiency of resources utilization, to provide sustainable resource supply for regional economic development.

The principle of reduction belongs to input methods are designed to reduce resources access to the process of production and consumption, aim at reducing the use of resources and pollutant emissions from source; the principle of re-use belonging to the process of approach, aims to improve the using efficiency of resource products and services, require resource products and packaging container to use time after time take the initial form and reduce environmental pollution; principle of recycling attribute to output method, requiring resources products to complete the function into a renewable resource after recycling; the principle of rethinking is for human resources and scientific and technological resources, require repeated use of its knowledge and technology; the principle of re-repair is mainly for the social and organizational resources, require to maintain the relationship between social networks and organizations to obtain more 
social resources to strengthen the economic body's organization and coordination capacity. In short, through the implementation of the principle 5R can be improved the recycling situation of resources, to provide the economic base and inexhaustible power for regional economic development.

3.2.2 Change the regional values; establish the concept of scientific development.

Publicize and promote recycling of resources, be enabling to change the traditional thinking and mode of development, erect a new concept of recycling-oriented society which is for scientific development, and actively advocate green consumption and waste separation, and establish the concept of sustainable consumption and life cultural approach which protest resource conservation, environmental protection. Ideas of resources recycling so as to increase and unity to view of uphold the people-oriented, comprehensive, coordinated and sustainable scientific development, and truly become idiographic embodiment for establishment and implementation of concept of scientific development, integrating the process of economic and social development, and effectively promote the regional economic sustainable development.

\subsubsection{Recycling of resources is to develop an effective way of recycling economy.}

The core meaning of circular economy is recycling of resources. In 2000, Professor of the NPC Environmental and Resources Committee Qu Geping clearly pointed out: "The so-called circular economy, in essence, is an eco-economy, it requires using the law of ecology rather than law of machinery to guide the economic activities of human society; recycling economy advocated an economic development model harmony with the environment, which requires organizing economic activity as the feedback process of ' resources - products - further resources', characterized by low mining, high-use, low-emission; all material and energy to be reasonable and sustainable used during this ongoing economic cycle, to reduce the impact on the natural environment by economic activities to the extent as small as possible. " in the article "development of circular economy is the general trend of the 21st century." This is a more complete summary for circular economy, and can be seen from this the core substance of circular economy is recycling of resources.

\section{Mechanism of Comprehensive Utilization of Resources}

\subsection{The Proposition of Comprehensive Utilization of Resources}

$<$ CPC Central Committee on the development of national economic and social development of the 10th Five-Year Plan Proposal > suggests, considering saving resources as a basic national policy, speeding up the construction of resource-saving and environment-friendly society, promoting economic development and population, resources and the environment coordination. This is the CPC Central Committee and State Council in the new situation made the major decision-making with strategic significance. Building a conservation-minded society must adhere to both development and conservation of resources, give priority to the principle of conservation in order to improve the efficiency of resource, and promote efficient utilization of resources and recycling. Comprehensive utilization of resources is a long-term strategic direction of a country's economic and social development also is a significant technical and economic policy, be of great significance to improve the efficiency of resource utilization, environmental protection, the promotion of economic growth mode from extensive to intensive changes in resource optimization allocation and sustainable development.

Comprehensive utilization of resources include: in the process of resource exploitation, make mineral symbiosis comprehensive development associated with rational use; recycling and rational use waste residue, waste liquid (water), emissions, heat, pressure, etc. which generated from the production process; recovery and recycling various waste materials for the social production and consumption process; establishing personnel and technology platform for the comprehensive utilization of resources, that is, create a dynamic collection and reserves high professional level of expertise or special talent in all areas as well as the information platform for advanced technology or scientific and technological achievements emerging in all fields, screening platform of the market to connect the main docking, the industries and markets multi-service platform for incubators, to achieve comprehensive utilization of technology and human resources.

\subsection{Contribution of Comprehensive Utilization of Resources to Enhance the Competitiveness of Regional Economy}

4.2.1 Comprehensive Utilization of Resources is an important measure to achieve sustainable use of resources, help to resolve the problem of resource shortage. Reducing the exploitation of primary resources, to enhance the level of comprehensive utilization of resources, not only to save a lot of resources, but also promoted the economic growth mode change from extensive to intensive. Therefore, efforts to raise the level of comprehensive utilization of resources are an important measure to promote the sustainable use of resources, help to protect resources and ease effectively the domestic resources shortage contradictions.

4.2.2 Comprehensive utilization of resources to protect effectively environment, reduce production costs, reduce even no emission of pollutants, able to protect an increasingly scarce natural resources and fragile ecological environment. At 
present, the volume of garbage has piled up more than 60 million tons, occupy land 500 million cubic meters, causing actual and potential pollution of soil, groundwater and atmosphere is quite serious. Therefore, actively promote the recycling of renewable resources is an important measure to control pollution.

4.2.3 Comprehensive utilization of resources can optimize energy structure; slow the depletion of non-renewable resources. Our energy resources structure are: petroleum, natural gas each accounted for $2.12 \%, 30 \%$ water, coal accounted for $65.16 \%$; and the current energy production and energy consumption structure are quite disproportionate resources, in general, coal accounted for $75 \%, 18 \%$ of crude oil, natural gas accounted for $2 \%, 5 \%$ for hydropower, nuclear power is a little number. Moreover, coal, oil and gas are non-renewable resources, and emissions from coal, slag is much higher than other fuels; water is a kind of renewable resources and no pollution, the question of resources for nuclear energy is relatively small. Weighing the pros and cons, it should be vigorously developed of water and electricity, proper construction of nuclear power, and as far as possible to reduce the coal, the proportion of oil consumption. For comprehensive utilization of resources, not only extended mining life of coal, oil and gas, but also reduce the pollution to a large extent, is conducive to economic growth.

4.2.4 Comprehensive utilization of resources but also expand the area of employment, help the people rich. From recycling to dismantling of waste and used materials are labor-intensive industries, so can effectively expanding employment channels for surplus labor in urban and rural area. In Taizhou Zhejiang dismantling base of scrap metal, direct employees up to more than 30,000, if add its services together with trade, transportation and other industries, the relevant employment for more than 10 million people. Therefore, upgrading the rate of resource utilization, it is especially important for manpower our current urban and rural economy and speeding up the process of building a new socialist countryside.

\section{Mechanism of Value-added Use of Resources}

\subsection{The Meaning of Value-added Use of Resources}

Value-added use of resources is defined as the process of resource utilization, the use of resources by increasing the link depth to improve the use of resources to develop new markets or find new uses for resources, etc., in order to increase the value of resources and their products. In this paper, it referred as value-added use of resources.

From the entire resources system, value-added use of resources specifically including: extending the industrial chain and increase the depth of processing resources, add additional value of resources and their products; to develop new markets and find new uses, to make innovative use of resources to obtain excessive profits; through advanced institutional arrangements, stimulate human resources and technology resources to continued innovation; for organizational resources and social resources, it means that play a multifaceted, multi-angle organization, coordination and cohesion capacity and social network as "information bridge" role, enhance the value of resources.

\subsection{The value-added use of resources in the region to enhance the competitiveness of the economy's performance}

5.2.1 Extending the industrial chain can increase the depth of resource products. Industry chain is essentially a value chain, each link of a production increase, it will increase the amount of abstract work in the pool of products, at the same time increase the technological content of products, improve product profit, thus increasing the value and additional value of products; then, this part of the increased value realized through market transactions, as money flows in the region, increase the region's currency inflows, improved regional terms of trade so that the region is in a good position in the market exchange, boost substantially the competitiveness of regional resources.

5.2.2 Develop new markets and find new uses for resources. Based on the original purpose of resources, to develop new markets, find new uses for the resources (including international business), which is also a kind of innovation. And innovation will bring excess profits for the region, and the length of its duration depends on the main barriers to entry and imitation behavior, that is, the higher the barriers to entry, the more difficult to imitate, the longer to reap excessive profits; or the more short. This excess of currency in order to increase inflows into the region, is bound to become economic support of regional economic competitiveness upgrading.

5.2.3 Using advanced institutional arrangements stimulate the sustainable innovation ability of human resources and science and technology resources. Regional governments and enterprises build advanced regional scientific and technological innovation system, create a strong atmosphere of scientific and technological innovation; At the same time, using the advanced institutional arrangements, mainly using the property rights system, clear property rights vested in human capital, effectively protect intellectual property rights, such as taking " Dry share, "' technology stocks "such as re-allocation of resources to" obtain the remaining right "to stimulate the continued ability to innovate of human resources, technology resources, to provide the "inexhaustible "power for regional economic development.

5.2.4 Play fully the coordination and cohesion capacity of organizational resources and "information bridge" role of social relations network. In market, if economic activity regulated by the mainstay of the economy depends entirely on the market mechanism, if there is external effects, public goods, monopolies and asymmetric information phenomenon, 
the market will expire, that is market failure. Therefore, we must in many ways and at regional level and give full play to the capacity of organization and coordination, to form cohesion of the main body of the regional economy; at the same time make full use of the "Information Bridge" role of social relations, resolve asymmetric information problems, to make up the negative economic effects brought about market failure, so that regional economy can develop stably and sustainable.

\section{References}

Feng, Zhiming \& Wang, Qinxue. (1994). Outline of the Resources of Science. Beijing: Earthquake Press.

Liu, Cunshou. (2006). To Strengthen the Comprehensive Utilization of Resources. China Nonferrous Metals, (7). 